$\xi=$

\title{
Grey theory based evaluation of importers' strategies for hedging the price risk in the Tanzanian oil supply chain: a focus on derivative products
}

\author{
Erick P. Massami ${ }^{1}$ *, Malima M. Manyasi ${ }^{1}$, Benitha M. Myamba ${ }^{2}$ \\ ${ }^{1}$ Dar Es Salaam Maritime Institute, Tanzania \\ ${ }^{2}$ National Institute of Transport, Tanzania \\ *Corresponding author E-mail: erick.massami@dmi.ac.tz
}

\begin{abstract}
The landed cost for oil products in local markets is very often affected by the fluctuation of price related to the international purchasing from oil markets. As a result, oil products are primarily procured via term contracts i.e. derivatives as wholesalers are typically loath to rely heavily on spot supplies as these may be unreliable and exhibit high price volatility. In this study, we apply Grey Theory to evaluate the derivatives based strategies of the Tanzanian oil products imports for hedging the price risk in the local market. After comprehensive evaluation, we find that the applicability of oil derivatives by the Tanzanian importers is high. Thus, the government (i.e. Ministry of Finance and Planning, Ministry of Trade and Industry) and other stakeholders have the obligation to continue bringing awareness on the benefits of the derivative instruments in the purchasing of oil products, which ultimately upon application would bring a relief to all consumers of the oil products in the country. Moreover, as the grey theory can deal with vague and incomplete data, the proposed model can be applied as an evaluation tool for quantifying qualitative data in any industry.
\end{abstract}

Keywords: Derivative Products; Grey Theory; Hedging; Oil Supply Chain; Price Risk.

\section{Introduction}

The landed cost i.e. price for oil products in a local market is generally affected by price fluctuations relating to the purchasing of these products from the world oil market. Tanzania has no exception. As such, oil products are primarily secured via term contracts, as wholesalers are typically loath to rely too heavily on spot supplies as these may be unreliable and exhibit high price volatility. Mega retailers (e.g. airlines, shipping lines etc.) operate similarly. An airline, for instance, usually secures supplies at airports from term suppliers rather than entering the spot market to fuel its fleet. Hence, the bulk of the oil products is sold through term contracts i.e. derivatives products, where a volume is agreed with a specified tolerance over a defined period. The tolerance is built in to provide flexibility to either the buyer or seller to load more or less than the contracted amount. Thus, importers of oil products in Tanzania can also play a significant role to reduce price risk exposure by employing derivatives product set. A variety of derivative instruments are available that allow supply chain members to lock in or hedge a price for oil deliveries in the future. These instruments include forwards, futures, options and swaps. Thus, evaluation of the applicability of derivatives is an important step for the price risk management of oil products in Tanzania. There are numerous evaluation methods proposed by researchers and/or practitioners in this respect including statistical and decision tools. Statistical methods, on one hand, necessitate much data hence found improper for this study due to the time and financial constraints. On the other hand, most of the decision tools including Analytical Hierarchy Process (AHP) method are not useful to deal with fuzzy and incomplete data. The contribution of this paper is to apply grey theory to evaluate the applicability of derivatives for hedging the price volatility by the Tanzanian importers of oil products. This paper is organized as follows: In Section 2 a description of derivative instruments is presented; Section 3 presents previous relevant studies; An overview of grey theory is presented in Section 4; A comprehensive evaluation model based on grey theory is developed in Section 5; Section 6 presents application of the Grey Set Theory to evaluate the applicability of derivatives by importers of oil products in Tanzania. Lastly, conclusions are given in Section 7.

\section{Description of derivatives instruments}

A derivative is a financial instrument whose value derives from the value of something else, generally called the underlying (e.g. A barrel of oil, a freight index). The derivative product set consists of forward contracts, futures contracts, swaps and options. The prices for these instruments are determined by applying the noarbitrage principle i.e. the profits cannot be realized without taking a risk. We describe each of the derivatives in the following sections. Oil products.

\subsection{Forward contracts}

A forward contract is an agreement to buy or sell a certain amount of an underlying i.e. oil products on a fixed date in the future, called the delivery time, for a price specified in advance, called the delivery price i.e. forward price. The party to the contract who agrees to sell the asset is said to be taking a short forward position. The other party, obliged to buy the asset at delivery, is said to 
have a long forward position. Forward contracts are bilaterally traded agreements between counterparties in the Over-the-counter (OTC) market i.e. a bilateral market in which deals are negotiated between counterparties, usually over the telephone. The forward contracts may trade in half-month, monthly or quarterly blocks. Let us denote the time when the forward contract is transacted by 0 , the delivery time by $\mathrm{T}$, the forward price by $\mathrm{F}(0, \mathrm{~T})$ and the market price at time $t$ of the underlying asset by $S(t)$. Either party makes no payment at time 0 , when the forward contract is exchanged. At delivery the party with a long forward position will benefit if $\mathrm{F}(0, \mathrm{~T})<\mathrm{S}(\mathrm{T})$. They can buy the asset for $\mathrm{F}(0, \mathrm{~T})$ and sell it for the market price $\mathrm{S}(\mathrm{T})$, making an instant profit of $\mathrm{S}(\mathrm{T})$ $\mathrm{F}(0, \mathrm{~T})$. Meanwhile, the party holding a short forward position will suffer a loss of $S(T)-F(0, T)$ because they will have to sell below the market price. The payoffs at delivery are $\mathrm{S}(\mathrm{T})-\mathrm{F}(0, \mathrm{~T})$ for a long forward position and $\mathrm{F}(0, \mathrm{~T})-\mathrm{S}(\mathrm{T})$ for a short position. If the contract is entered into at any time $t<T$, then we denote $F(t, T)$ for the forward price, the payoff at delivery being $\mathrm{S}(\mathrm{T})-\mathrm{F}(\mathrm{t}, \mathrm{T})$ for a long forward position and $F(t, T)-S(T)$ for a short position. Nevertheless, the seller may not deliver the oil products at the agreed price i.e. the credit risks involved in entering forward contracts act as a deterrent to their use. Thus, the default risk problem of the forward contract has led financial intermediaries to develop futures contracts where the credit risk can be greatly reduced

\subsection{Futures contracts}

A futures contract is a contract between two parties - a buyer and a seller - to buy or sell something at a future date at a price agreed upon today. The contract trades under standardized terms on a futures exchange i.e. futures markets and is subject to a daily settlement procedure. Deals are agreed bilaterally, either electronically on screens or through open outcry in a trading pit, but are executed with the exchange through a process known as novation. In novation, a deal is split into two legs, a purchase and sale, and each leg is executed with the exchange as counterparty. Futures deals may or may not involve physical delivery of a commodity i.e. oil product, depending on the underlying contract terms. In oil market, the New York Mercantile Exchange (NYMEX) and Intercontinental Exchange (ICE) are the key futures exchanges. Unlike futures contracts, option contracts require no margin calls, can take advantage of favourable price moves and have limited risk i.e. the maximum potential loss is known when the option is purchased.

\subsection{Option contracts}

An option is a contract between two parties - a buyer and a seller that gives the option buyer or seller the right, but not the obligation, to purchase or sell something at a later date at a price agreed today. An option to buy something is referred to as a call; an option to sell something is called a put. Options trade in either organized markets i.e. options exchanges or conducted privately between two parties i.e. the over-the-counter market. In contrast to option contracts, swap contracts do not require the payment of premium upfront and have the same symmetric or linear payoff profile as forwards and futures. However, they differ from forwards and futures in that there is a multiplicity of cash flows between the two counter parties over the life of the swap.

\subsection{Swaps contracts}

A swap is a contract in which two parties agree to exchange stream of benefits or payments. For example, a wholesaler of oil products is currently receiving a certain amount of oil products at regular intervals from one supplier but would prefer exchanging the stream with another wholesaler who is receiving the amount of oil products at irregular intervals from another supplier. The party contacts a Swap dealer, a firm operating in the over-the-counter market, who takes the opposite side of the transaction. The two parties, in effect, swap streams of the amount of oil products received. Depending on what later happens to prices of oil products, one party might gain at the expense of the other. Swaps are usually tailor-made i.e. traded OTC, although some swap products are traded on exchanges such as ICE.

\section{Previous relevant studies}

There are many studies that investigate oil risk exposure in various supply chains. Shaeri et al. [1] use the Fama-French five-factor model to examine the oil price risk exposure of US financial and non-financial subsectors and find that the non-financial subsectors are more affected by oil prices than the financial subsectors. Liu et al. [2] apply panel models for identification and analysis of influence of oil price volatility on statistical properties of country risk ratings, which stem from uncertainty of macroeconomic fluctuations and find that country risk remains comparatively steady despite of oil price volatility. Kakeu and Bouaddi [3] use an econometric method based on dynamic factor analysis for estimating the pricing equation of oil stocks and find that oil investors care about long-run risks associated with future growth prospects. Lux et al. [4] apply the Markov-switching multifractal (MSM) model and a battery of generalized autoregressive conditional heteroscedasticity $(\mathrm{GARCH})$-type models to forecast oil price volatility. Nazlioglu et al. [5] examine the role of oil price shocks and volatility on six REIT categories and find uni-directional causality running from oil prices to all REITs, except for the mortgage REITs. Kristjanpoller and Minutolo [6] use ANN-GARCH model to predict oil price return volatility and find that the ANN model improves the accuracy of the GARCH model. Guo et al. [7] apply the ARJGARCH models to find the relationship between the world oil price and China's coke price. The empirical results show negative oil price shocks lead to falls in China's coke returns on the following day while positive oil prices have no significant effects. Pal and Mitra [8] apply Multiple Threshold Nonlinear Autoregressive Distributed Lag (MTNARDL) model to assess asymmetric impact of crude oil price changes on oil product pricing. The empirical results reveal that the price of oil products increases when crude prices go up. Sun et al. [9] re-examine the risk of oil imports from the perspective of global oil supply chain and design a standardized framework of four risk factors i.e. availability, accessibility, affordability and acceptability. Wang and Wang [10] propose a new forecasting model based on random Elman recurrent neural network to forecast the accuracy of crude oil price fluctuations. Tiwari and Albulescu [11] use a wavelet approach and asymmetric, multi-horizon Granger-causality tests to assess the relationship between the oil price and India-US real exchange rate. Ahmadi et al. [12] apply Structural Autoregressive (SVAR) model to investigate the effects of oil price shocks on volatility of agricultural and metal commodities in US. The results reveal that the response of volatility of each commodity to an oil price shock differs significantly depending on the underlying cause of the shock for the period under consideration. Mnasri et al. [13] investigate the motivations and value effect of nonlinear hedges and reveal that oil producers with a higher propensity to use pure nonlinear hedging strategies tend to have higher marginal firm value. Liu et al. [14] use SVAR to disentangling oil price determinants from the US and China. The empirical results reveal that oil price changes in recent years are mainly caused by demand shocks. Zhang and Xie [15] evaluate China's product pricing mechanism based on a 14 year span of monthly data and reveal that the mechanism does not appear to respond asymmetrically to international oil price. Ji et al. [16] analyse the impact of global economic activity and international crude oil prices on natural gas import prices in three major natural gas markets using the panel cointegration model. The results show that the response of natural gas import prices to oil prices up and down shows asymmetry. Chen et al. [17] use a Grey wave-forecasting model to predict multi-step-ahead crude oil price. In order to curb the oil price risk volatility, most researchers and practitioners propose the use of Derivative products. Guay [18] examines derivatives' roles in a firm and reveal that the firm risk 
(measured several ways) declines following derivatives use. Ma et al. [19] provide a new perspective of modelling and forecasting realized range-based volatility (RRV) for crude oil futures and find that the results are robust to different forecasting windows and forecasting horizons. Phan et al. [20] investigate the role of derivatives in enhancing firm value of US oil and gas exploration and production companies over the period of 1998-2009, using both cross-sectional and time-series tests. Turner and Lim [21] use daily data over the past two decades to determine the minimum variance hedge ratio for airlines wishing to hedge jet fuel price risk with futures, meanwhile establishing the best cross hedging asset. Derivatives have been proven to be effective and efficient tools for the management of oil price risk in developed countries. Thus, it is vital to evaluate the applicability of these tools in the Tanzanian oil product supply chains. There are various evaluation tools proposed in the literature. However, the Grey Theory, which is the general case of the Fuzzy Theory, is more useful for tackling problems with fuzziness.

Yu et al. [22] present and demonstrate a methodology for evaluating a micro-surfacing treatment on asphalt pavement based on the grey stem model and grey relational degree theory. Zhicheng et al [23] apply Grey correlation theory and Computational Fluid Dynamics (CFD) simulation to optimize the shape of a Welded Plate Heat Exchanger (WPHE) with straight gas channels and corrugated water channels. Rajeswari and Amirthagadeswaran [24] apply RSM based grey relational analysis to investigate the machinability characteristics of end milling operation to yield the minimum surface roughness cutting force, tool wear with the maximum material removal rate. Baruah et al. [25] apply grey relational analysis in the optimization of incremental sheet metal formation of AA5052. Mathivathanan et al. [26] use Grey-Analytical Hierarchy Process to explore the impact of dynamic capabilities on sustainable supply chain performance of a firm. Thakur and Ramesh [27] propose a Multi-Attribute Decision-Making (MADM) model based on grey theory for optimal selection of waste disposal firm. Wei et al. [28] apply grey theory to evaluate work safety in Mainland China. Yan et al. [29] apply trapezoid grey relational degree method to improve the calculation of the Canadian Council of Ministers of the Environment Water Quality Index. Golinska et al. [30] apply Grey Decision Making for the classification of the sustainability level of remanufacturing companies. Chithambaranathan et al. [31] use a grey-based hybrid framework to evaluate the environmental performance of service supply chains. Rajesh and Ravi [32] use a grey relational analysis approach to select supplier in resilient supply chains. Baskaran et al. [33] apply the grey approach to evaluate suppliers' within the Indian textile and clothing industry using the sustainability criteria. Celikbilek and Tüysüz [34] present a grey-based multi-criteria decision model for the evaluation of renewage energy sources.

The objective of this study is to understand in linguistic terms the extent of the application of Derivatives by the Tanzanian importers when purchasing oil products. The Grey Theory is applied as a Decision Making Tool (DMT) since it has proven to be effective and efficient evaluation tool for problems involving fuzziness as the assessor's score on a particular Factor i.e. application of Derivative type is given as an interval whose lower and upper values are known.

\section{Overview of grey theory}

Deng [35] introduced grey theory. A grey set $G$ on the universal set $X$ is defined by two membership functions: $\mu_{G}(x)$ and

$$
\begin{aligned}
& \overline{\mu_{\mathrm{G}}}(\mathrm{x}) \text { Where } \underline{\mu_{\mathrm{G}}}(\mathrm{x}) \leq \overline{\mu_{\mathrm{G}}}(\mathrm{x}) ;\left[\underline{\mu_{\mathrm{G}}}(\mathrm{x}), \overline{\mu_{\mathrm{G}}}(\mathrm{x})\right] \\
& \underline{\mu_{\mathrm{G}}}(\mathrm{x}): \mathrm{x} \rightarrow[0,1] ; \overline{\mu_{\mathrm{G}}}(\mathrm{x}): \mathrm{x} \rightarrow[0,1] \\
& \underline{\mu_{\mathrm{G}}}(\mathrm{x})=\inf \left\{\mu_{\mathrm{G}}(\mathrm{x}), \forall \mathrm{x} \in \mathrm{X}\right\} ; \overline{\mu_{\mathrm{G}}}(\mathrm{x})=\sup \left\{\mu_{\mathrm{G}}(\mathrm{x}), \forall \mathrm{x} \in \mathrm{X}\right\}
\end{aligned}
$$

$\mu_{\mathrm{G}}(\mathrm{x})$ and $\overline{\mu_{\mathrm{G}}}(\mathrm{x})$ are respectively the lower and upper membership functions of $\mathrm{G}$. If $\mu_{\mathrm{G}}(\mathrm{x})=\overline{\mu_{\mathrm{G}}}(\mathrm{x}), \mathrm{G}$ becomes a fuzzy set. Thus, a fuzzy set is a special case of a grey set.

Grey sets are expressed in terms of grey numbers. A grey number is a number whose numerical value is unknown, but the interval that encompasses it, is known. According to Yang and John [36], a grey number is a number with clear upper and lower boundaries but which has an unknown position within the boundaries. Generally, a grey number corresponding to a grey set $\mathrm{G}$ is denoted as $\otimes$ $\mathrm{G}$. When both the lower and upper limits of the interval can be estimated then $\otimes G=[\underline{G}, \bar{G}]$. If only the lower limit of the interval is possible to be estimated, then $\otimes G=[\underline{G}, \infty)$. If only the upper limit of the interval is possible to be estimated, then $\otimes G=$ $(-\infty, \overline{\mathrm{G}}]$. Nonetheless, Grey numbers can be applied into various operations.

\section{Basic Operations on Grey Numbers}

Grey number operations are operations defined on sets of intervals. Liu et al. [37] state that the arithmetic of grey numbers is similar to the arithmetic of interval values. Suppose $\otimes G_{1}=$ $\left[\underline{G_{1}}, \overline{G_{1}}\right], \otimes G_{2}=\left[\underline{G_{2}}, \overline{G_{2}}\right]$ a $\in \mathbb{R}_{+}$, then the following four basic operations on grey numbers are true.

$$
\begin{aligned}
& \otimes G_{1}+\otimes G_{2}=\left[\underline{G_{1}}+\underline{G_{2}}, \overline{G_{1}}+\overline{G_{2}}\right] \\
& \otimes G_{1}-\otimes G_{2}=\left[\underline{G_{1}}-\overline{G_{2}}, \overline{G_{1}}-\underline{G_{2}}\right] \\
& \mathrm{a} \otimes \mathrm{G}_{1}=\left[\underline{\mathrm{aG}}, \mathrm{a} \overline{\mathrm{G}_{1}}\right] \\
& \otimes G_{1} \times \otimes G_{2}=\left[\begin{array}{l}
\min \left(\underline{G_{1}} \underline{G_{2}}, \underline{G_{1}} \overline{G_{2}}, \overline{G_{1}} \underline{G_{2}}, \overline{G_{1}} \overline{G_{2}}\right), \\
\max \left(\underline{G_{1}} \underline{G_{2}}, \underline{G_{1}} \overline{G_{2}}, \overline{G_{1}} \underline{G_{2}}, \overline{G_{1}} \overline{G_{2}}\right)
\end{array}\right] \\
& \otimes G_{1} \div \otimes G_{2}=\left[\underline{G_{1}}, \overline{G_{1}}\right] \times\left[\frac{1}{\overline{G_{2}}}, \frac{1}{G_{2}}\right]
\end{aligned}
$$

The length of $\otimes G$ is defined as

$$
L(\otimes G)=[\bar{G}-\underline{G}]
$$

\section{Comprehensive evaluation modelling based on grey theory}

We develop the Grey Comprehensive Evaluation Model (GCEM), which consists of the following sequential steps:

Step 1: Establish Vague Judgement Number of Importance (i.e. Vague Assessment Scale). In this study, we use an extended scale to the one suggested by Massami and Myamba [38]. This scale has 0.0 as the lower bound and 1.0 as the upper bound. The scale has six (6) intervals. With the exception of the first interval, each has the width of 0.2 units. The relation between linguistic operator of importance and Grey Judgement Number of Importance is listed in table 1.

Step 2: Establish Grey Judgement Table of Importance (GJTI) of the factor for an objective under consideration as represented in table 2 . 
Table 1: Relationship between Grey Judgement Number of Importance and Linguistic Term

\begin{tabular}{lccccc}
\hline $\begin{array}{l}\text { Grey Judgement } \\
\text { Number }\end{array}$ & {$[0.0,0.0]$} & {$[0.0,0.2]$} & {$[0.2,0.4]$} & {$[0.4,0.6]$} & {$[0.6,0.8]$} \\
\hline Importance & None & Very Low & Low & Moderate & High \\
\hline
\end{tabular}

Table 2: Grey Judgement Table of the Factor for the Given Objective

\begin{tabular}{|c|c|c|c|c|c|}
\hline Factor $\left(\mathrm{F}_{\mathrm{i}}\right)$ & $S_{1}$ & $\mathrm{~S}_{2}$ & $\ldots$ & $\mathrm{S}_{\mathrm{J}}$ & $\frac{1}{J} \sum_{j=1}^{J}\left[\underline{\mu}_{G}^{i j}(x),{\overline{\mu_{G}}}^{i j}(x)\right]$ \\
\hline $\mathrm{F}_{1}$ & {$\left[{\underline{\underline{\mu_{G}}}}^{11}(x),{\overline{\mu_{G}}}^{11}(x)\right]$} & {$\left[{\underline{\mu_{G}}}^{12}(x),{\overline{\mu_{G}}}^{12}(x)\right]$} & $\cdots$ & {$\left[{\underline{\mu_{G}}}^{1 J}(x),{\overline{\mu_{G}}}^{1 J}(x)\right]$} & $\frac{1}{J} \sum_{j=1}^{J}\left[\underline{\mu}^{1 j}(x),{\overline{\mu_{G}}}^{1 j}(x)\right]$ \\
\hline $\mathrm{F}_{2}$ & {$\left[\underline{\mu}_{G}^{21}(x),{\overline{\mu_{G}}}^{21}(x)\right]$} & {$\left[\underline{\mu}_{G}^{22}(x),{\overline{\mu_{G}}}^{22}(x)\right]$} & $\ldots$ & {$\left[{\underline{\mu_{G}}}^{2 J}(x),{\overline{\mu_{G}}}^{2 J}(x)\right]$} & $\frac{1}{J} \sum_{j=1}^{J}\left[\underline{\mu}_{G}{ }^{2 j}(x),{\overline{\mu_{G}}}^{2 j}(x)\right.$ \\
\hline$\vdots$ & & $\vdots$ & $\ldots$ & $\vdots$ & $\vdots$ \\
\hline $\mathrm{F}_{\mathrm{I}}$ & {$\left[\underline{\mu}_{G}^{I 1}(x),{\overline{\mu_{G}}}^{I 1}(x)\right]$} & {$\left[\underline{\mu}_{G}^{I 2}(x),{\overline{\mu_{G}}}^{I 2}(x)\right]$} & $\ldots$ & {$\left[\underline{\mu}_{G}^{I J}(x),{\overline{\mu_{G}}}^{I J}(x)\right]$} & $\frac{1}{J} \sum_{j=1}^{J}\left[\underline{\mu}_{G}^{I j}(x),{\overline{\mu_{G}}}^{I j}(x)\right]$ \\
\hline
\end{tabular}

Step 3: Construction of Weight Matrix

We use the values of the last column of table 2 to compute the normalized grey weight of factor $\mathrm{i}\left(W_{F_{i}}\right)$ as given in equation (9).

$W_{F_{i}}=\frac{\frac{1}{J} \sum_{j=1}^{J}\left[{\underline{\mu_{G}}}^{i j}(x),{\overline{\mu_{G}}}^{i j}(x)\right]}{\sum_{l=1}^{I}\left(\frac{1}{J} \sum_{j=1}^{J}\left[{\underline{\underline{\mu_{G}}}}^{l j}(x),{\overline{\mu_{G}}}^{l j}(x)\right]\right)}, l \in\{1,2, \ldots I\}$

Where $W_{F_{i}} \subseteq[0.0,1.0], i \in\{1,2, \ldots I\}$

After cancellation of $\frac{1}{J}$ in equation (10), we get another form of equation (10) which is written as equation (11).

$$
W_{F_{i}}=\frac{\sum_{j=1}^{J}\left[{\underline{\mu_{G}}}^{i j}(x),{\overline{\mu_{G}}}^{i j}(x)\right]}{\sum_{l=1}^{I}\left(\sum_{j=1}^{J}\left[{\underline{\mu_{G}}}^{l j}(x),{\overline{\mu_{G}}}^{l j}(x)\right]\right)}, l \in\{1,2, \ldots I\}
$$

Thus,

The matrix of the normalized weights is given by equation (11).

$W=\left[W_{F_{i}}\right], i \in\{1,2, \ldots I\}$

Step 4: Formulate a Single Factor Grey Evaluation Matrix The single factor grey evaluation matrix is a Normalized Grey Decision Matrix (NGDM).

In order to construct a Grey Decision Matrix (D), we develop a Grey Relational Analysis (GRA) with the following steps.

Step a: Formulate a Grey Decision Matrix (D) whose elements are given in table 3 .

Table 3: Grey Evaluation Table for Factor $F_{m}, m \in\{1,2, \ldots M\}$

\begin{tabular}{llccc}
\hline $\begin{array}{l}\text { Factor } \\
\left(\mathrm{F}_{\mathrm{m}}\right)\end{array}$ & $S_{1}=\left[L_{1}, U_{1}\right]$ & $S_{2}=\left[L_{2}, U_{2}\right]$ & $\ldots$ & $S_{N}=\left[L_{N}, U_{N}\right]$ \\
\hline $\mathrm{F}_{1}$ & {$\left[{\underline{\mu_{G}}}^{11}(x),{\overline{\mu_{G}}}^{11}(x)\right]$} & {$\left[\underline{\mu}_{G}{ }^{2}(x),{\overline{\mu_{G}}}^{12}(x)\right]$} & $\ldots$ & {$\left[{\underline{\mu_{G}}}^{1 N}(x),{\overline{\mu_{G}}}^{1 N}(x)\right]$} \\
$\mathrm{F}_{2}$ & {$\left[{\underline{\mu_{G}}}^{21}(x),{\overline{\mu_{G}}}^{21}(x)\right]$} & {$\left[{\underline{\mu_{G}}}^{22}(x),{\overline{\mu_{G}}}^{22}(x)\right]$} & $\ldots$ & {$\left[\underline{\underline{\mu}}^{2 N}(x),{\overline{\mu_{G}}}^{2 N}(x)\right]$} \\
$\vdots$ & $\vdots$ & $\vdots$ & $\ldots$ & $\vdots$ \\
$\mathrm{F}_{\mathrm{M}}$ & {$\left[{\underline{\underline{\mu_{G}}}}^{M 1}(x),{\overline{\mu_{G}}}^{M 1}(x)\right]$} & {$\left[{\underline{\underline{\mu_{G}}}}^{M 2}(x),{\overline{\mu_{G}}}^{M 2}(x)\right]$} & $\ldots$ & {$\left[\underline{\mu}^{M N}(x),{\overline{\mu_{G}}}^{M N}(x)\right]$} \\
\hline
\end{tabular}

Note: $\left[L_{k}, U_{k}\right]$ is a Grey assessment scale and $L_{k+1}=U_{k}, \forall k \in$ $\{1,2, \ldots N-1\} ;[0.0,0.0]$ means none value corresponds to the linguistic scale.

From table 3, we deduce the elements of the grey decision matrix

(D) which is given by equation (12).

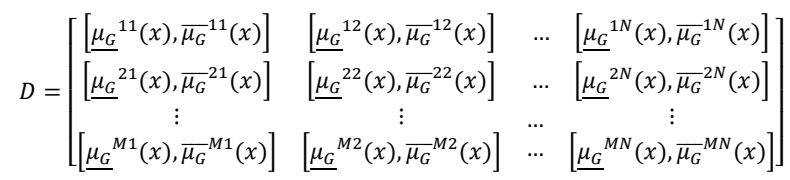

Step b: Generate a Referential Series (Do) of optimal values.

$D_{O}=\left(\left[\underline{\mu}_{G}^{s}(x),{\overline{\mu_{G}}}^{s}(x)\right]\right), \forall s \in\{1,2, \ldots N\}$

Where,
$\left[\underline{\mu_{G}} \underline{G}^{s}(x),{\overline{\mu_{G}}}^{s}(x)\right]$

$=\left\{\begin{array}{c}\max _{1 \leq m \leq M}\left[{\underline{\mu_{G}}}^{m n}(x),{\overline{\mu_{G}}}^{m n}(x)\right],\left[L_{n}, U_{n}\right] \text { is a Scale for Benefit criterion } \\ \min _{1 \leq m \leq M}\left[\underline{\underline{\mu}}^{m n}(x),{\overline{\mu_{G}}}^{m n}(x)\right],\left[L_{n}, U_{n}\right] \text { is a Scale for Cost criterion } \\ \frac{1}{\mathrm{M}} \sum_{m=1}^{M}\left[{\underline{\mu_{G}}}^{m n}(x),{\overline{\mu_{G}}}^{m n}(x)\right],\left[L_{n}, U_{n}\right] \text { is a Scale for Standard criterion }\end{array}\right.$

Step $c$ : Formulate a Normalized Grey Decision Matrix (NGDM).

$D^{*}$
$=\left[\begin{array}{cccc}{\left[\underline{\mu}^{11 *}(x),{\overline{\mu_{G}}}^{11 *}(x)\right]} & {\left[\underline{\mu}^{12 *}(x),{\overline{\mu_{G}}}^{12 *}(x)\right]} & \cdots & {\left[\underline{\mu}^{1 N *}(x),{\overline{\mu_{G}}}^{1 N *}(x)\right]} \\ \left.\underline{\mu}^{21 *}(x),{\overline{\mu_{G}}}^{21 *}(x)\right] & {\left[\underline{\mu}^{22 *}(x),{\overline{\mu_{G}}}^{22 *}(x)\right]} & \ldots & {\left[\underline{\mu}^{2 N *}(x),{\overline{\mu_{G}}}^{2 N *}(x)\right]} \\ \vdots & \vdots & \ldots & \vdots \\ {\left[\underline{\mu}^{M 1 *}(x),{\overline{\mu_{G}}}^{M 1 *}(x)\right]} & {\left[\underline{\mu}^{M 2 *}(x),{\overline{\mu_{G}}}^{M 2 *}(x)\right]} & \cdots & {\left[\underline{\mu}^{M N *}(x),{\overline{\mu_{G}}}^{M N *}(x)\right]}\end{array}\right]$

Where $\left[\underline{\mu}_{G}^{m n *}(x), \bar{\mu}_{G}^{m n *}(x)\right]$ is computed by using one of the following three formulas depending on whether a particular grey assessment value is a cost criterion, benefit criterion or neither of the two i.e. standard criterion.

For a Benefit Criterion:

$\left[{\underline{\mu_{G}}}^{m n *}(x),{\overline{\mu_{G}}}^{m n *}(x)\right]=$

$\left[\underline{\mu}_{G}^{m n}(x),{\overline{\mu_{G}}}^{m n}(x)\right]-\min _{m}\left\{\left[{\underline{\mu_{G}}}^{m n}(x),{\overline{\mu_{G}}}^{m n}(x)\right]\right\}$

$\max _{m}\left\{\left[{\underline{\mu_{G}}}^{m n}(x),{\overline{\mu_{G}}}^{m n}(x)\right]\right\}-\min _{m}\left\{\left[{\underline{\mu_{G}}}^{m n}(x),{\overline{\mu_{G}}}^{m n}(x)\right]\right\}$

For a Cost Criterion:

$\left[{\underline{\mu_{G}}}^{m n *}(x),{\overline{\mu_{G}}}^{m n *}(x)\right]=$

$\frac{\max _{m}\left\{\left[{\underline{\mu_{G}}}^{m n}(x),{\overline{\mu_{G}}}^{m n}(x)\right]\right\}-\left[\underline{\underline{\mu}}^{m n}(x),{\overline{\mu_{G}}}^{m n}(x)\right]}{\max _{m}\left\{\left[\underline{\mu}_{G}^{m n}(x),{\overline{\mu_{G}}}^{m n}(x)\right]\right\}-\min _{m}\left\{\left[\underline{\mu}_{G}^{m n}(x),{\overline{\mu_{G}}}^{m n}(x)\right]\right\}}$

For a Standard Criterion:

$\left[\underline{\mu}_{G}^{m n *}(x),{\overline{\mu_{G}}}^{m n *}(x)\right]$

$=\frac{\left[{\underline{\mu_{G}}}^{m n}(x),{\overline{\mu_{G}}}^{m n}(x)\right]-\left[\underline{\underline{\mu}}^{s}(x),{\overline{\mu_{G}}}^{s}(x)\right]}{\max _{m}\left\{\left[{\underline{\mu_{G}}}^{m n}(x),{\overline{\mu_{G}}}^{m n}(x)\right]\right\}-\left[\underline{\mu}^{s}(x),{\overline{\mu_{G}}}^{s}(x)\right]}$

Step 5: Grey Comprehensive Evaluation

Now the grey comprehensive evaluation is considered based on all factors and it is a product of the normalized weighted matrix and single factor grey evaluation matrix.

Thus,

$B=\left[W_{F_{m}}\right]\left[\left[\underline{\mu}_{G}^{m n *}(x),{\overline{\mu_{G}}}^{m n *}(x)\right]\right]$

Step 6: Compute the Overall Evaluation Value

By applying the principle of maximum degree of importance to the comprehensive evaluation result, we can determine evaluation 
value for the objective under consideration i.e. A Grey number with the largest kernel.

Thus, Evaluation Value $(\mathrm{EV})=\max \left(\frac{1}{2}\left[{\underline{\mu_{G}}}^{m n}+{\overline{\mu_{G}}}^{m n}\right]\right)$

Nevertheless, the result may be biased for not taking into accoun the contribution of other members in the comprehensive evaluation set. We thus, deal with B further to make it a single value by using equation (19).

$U=B \cdot C^{T}$

Where,

$C=[[0.0,0.2],[0.2,0.4],[0.4,0.6],[0.6,0.8],[0.8,1.0]]$

Let $\alpha$ be the value given by equation (19). If $\alpha \in[0.0,0.0]$ then the value of the objective under consideration is none; If $\alpha \in$ $[0.0,0.2]$ then the value of the objective under consideration is very low; If $\alpha \in[0.2,0.4]$ then the value of the objective under consideration is low; If $\alpha \in[0.4,0.6]$ then the value of the objective under consideration is moderate; If $\alpha \in[0.6,0.8]$ then the value of the objective under consideration is high; If $\alpha \in[0.8,1.0]$ then the value of the objective under consideration is very high.

\section{Application of the grey theory based com- prehensive model to evaluate the applicabil- ity of oil derivatives in Tanzania}

Traditionally, Oil marketing companies used to purchase oil products directly from production sources (e.g. Oil Producing and Exporting Countries (OPEC)). This system has been abolished as a result of many malpractices (e.g. Price cartel) exercised by these companies. Thus the Government of Tanzania decided to establish the PETROLEUM BULK PROCUREMENT AGENCY (PBPA) by Government Notice No. 423 of 2015 to coordinate the importation through the use of international competitive tender system on behalf of the purchasers (i.e. Oil marketing companies). The TPBPA has variety of derivatives instruments that can be engineered for and on behalf of Tanzanian oil importers i.e. wholesalers to lock in or hedge a price for deliveries in the future. These oil derivatives are shown in table 4

Table 4: Derivatives Product Set for Hedging Oil Price Risk

\begin{tabular}{ll}
\hline Objective & Criterion - Oil deriva- \\
& tive $\left(\mathrm{F}_{\mathrm{m}}\right)$ \\
\hline & $\mathrm{F}_{1}$ : Oil Futures \\
Evaluation of the applicability of derivatives for & $\mathrm{F}_{2}$ : Oil Forwards \\
hedging oil price risk & $\mathrm{F}_{3}$ : Oil Options \\
& $\mathrm{F}_{4}$ : Oil Swaps \\
\hline
\end{tabular}

In order to evaluate the applicability of oil derivatives by the Tanzanian oil importers we divide the scale into six levels: None, Very Low, Low, Moderate, High and Very High. As the boundaries of these scales are vague and sometimes incomplete, we use Grey Theory to describe them. Thus, the evaluation set,

$\mathrm{E}=\{$ None, Very Low, Low, Moderate, High, Very High $\}=\{[0.0$, $0.0],[0.0,0.2],[0.2,0.4],[0.4,0.6],[0.6,0.8],[0.8,1.0]\}$.

\subsection{Construction of weight matrix}

An interview with the Tanzania Petroleum Bulk Procurement Agency (TPBPA) on the assessment of the application of Oil Derivatives gave the following Grey Judgement Table of Importance (GJTI) i.e. Table 5

We use equations (9) and (10) to obtain the matrix of the normalized weights as given by equation (20).
Table 5: Grey Judgement Table of Importance for the Assessment of Oil Derivatives

\begin{tabular}{ccccccl}
\hline $\mathrm{F}_{\mathrm{i}}$ & $\mathrm{VL}$ & $\mathrm{L}$ & $\mathrm{M}$ & $\mathrm{H}$ & $\mathrm{VH}$ & $\frac{1}{J} \sum_{j=1}^{J}\left[\underline{\mu}_{G}{ }^{i j}(x),{\overline{\mu_{G}}}^{i j}(x)\right]$ \\
\hline $\mathrm{F}_{1}$ & {$[0.0,0.0]$} & {$[0.0,0.0]$} & {$[0.0,0.0]$} & {$[0.0,0.0]$} & {$[0.8,1.0]$} & {$[0.16,0.20]$} \\
$\mathrm{F}_{2}$ & {$[0.0,0.2]$} & {$[0.0,0.0]$} & {$[0.0,0.0]$} & {$[0.0,0.0]$} & {$[0.0,0.0]$} & {$[0.00,0.04]$} \\
$\mathrm{F}_{3}$ & {$[0.0,0.0]$} & {$[0.0,0.0]$} & {$[0.0,0.0]$} & {$[0.0,0.0]$} & {$[0.8,1.0]$} & {$[0.16,0.20]$} \\
$\mathrm{F}_{4}$ & {$[0.0,0.0]$} & {$[0.0,0.0]$} & {$[0.0,0.0]$} & {$[0.0,0.0]$} & {$[0.8,1.0]$} & {$[0.16,0.20]$}
\end{tabular}

$W=[[0.25,0.42],[0.00,0.08],[0.25,0.42],[0.25,0.42]]$

The findings reveal that Tanzanian oil importers often apply oil futures, oil options and oil swaps to hedge the price risk of oil products in the local market and they rarely apply oil forwards. Thus the Tanzanian oil importers are not interested in taking a credit risk inherited in the forward contracts which could lead to counterparty default. Nonetheless, forward contracts have inherent flexibility as are negotiated privately and can be modified to meet both parties' needs.

\subsection{Construction of single factor grey evaluation matrix}

We use the results of the interview to construct the grey decision matrix (D) as given by equation (21).

$D=$

$\left[\begin{array}{lllll}{[0.0,0.0]} & {[0.0,0.0]} & {[0.0,0.0]} & {[0.0,0.0]} & {[0.8,1.0]} \\ {[0.0,0.2]} & {[0.0,0.0]} & {[0.0,0.0]} & {[0.0,0.0]} & {[0.0,0.0]} \\ {[0.0,0.0]} & {[0.0,0.0]} & {[0.0,0.0]} & {[0.0,0.0]} & {[0.8,1.0]} \\ {[0.0,0.0]} & {[0.0,0.0]} & {[0.0,0.0]} & {[0.0,0.0]} & {[0.8,1.0]}\end{array}\right]$

\subsection{Construction of a normalized grey decision matrix}

We use equations (14), (15) and (16) and grey decision matrix (D) to deduce the Normalized Grey Decision Matrix $\left(D^{*}\right)$ as given by equation (22).

$D^{*}=$

$\left[\begin{array}{ccccc}{[0.0, \infty]} & {[0.0,0.0]} & {[0.0,0.0]} & {[0.0,0.0]} & {[0.8,1.25]} \\ {[-\infty, \infty]} & {[0.0,0.0]} & {[0.0,0.0]} & {[0.0,0.0]} & {[0.0,0.0]} \\ {[0.0, \infty]} & {[0.0,0.0]} & {[0.0,0.0]} & {[0.0,0.0]} & {[0.8,1.25]} \\ {[0.0, \infty]} & {[0.0,0.0]} & {[0.0,0.0]} & {[0.0,0.0]} & {[0.8,1.25]}\end{array}\right]$

$[\underline{G}, \bar{G}] \subseteq[0,1] \rightarrow[0.0, \infty]=[-\infty, \infty]=[0.0,1.0][0.8,1.25]=$ $[0.8,1.00]$

$\mathrm{D}^{*}=$

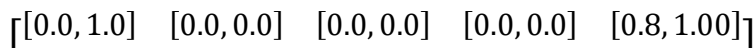

$\left[\begin{array}{lllll}{[0.0,1.0]} & {[0.0,0.0]} & {[0.0,0.0]} & {[0.0,0.0]} & {[0.0,0.0]}\end{array}\right.$

$\left[\begin{array}{lllll}{[0.0,1.0]} & {[0.0,0.0]} & {[0.0,0.0]} & {[0.0,0.0]} & {[0.8,1.00]}\end{array}\right.$

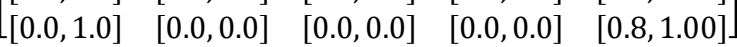

\subsection{Grey theory comprehensive evaluation for the ap-} plicability of derivatives by Tanzanian oil importers

We multiply the weight matrix (W) and the normalized grey decision matrix $\left(\mathrm{D}^{*}\right)$ to give the grey comprehensive evaluation matrix (B). That is, $\mathrm{B}=\mathrm{W} \cdot \mathrm{D}^{*}$

$\mathrm{B}=$

$([0.0,1.0] \quad[0.0,0.0] \quad[0.0,0.0] \quad[0.0,0.0] \quad[0.6,1.0])$

Now,

B. $C^{\mathrm{T}}=([0.48,1.00])$

$\mathrm{EV}=0.74 \in[0.6,0.8]$

Thus the applicability of oil derivatives by the Tanzanian oil importers is high. The TPBPA is advised on behalf of Oil marketing companies to keep up applying oil derivatives to hedge against adverse movement of oil price in the local market which in turn 
may reduce inflation, hence improve the national economy. However, mandating one entity i.e. TPBPA to enter into contract of sale to purchase all oil products on behalf of oil product importers may not promote the growth of Oil derivative markets in Tanzania and hence lead to inefficiency in the oil product supply chains and illiquidity of Oil derivative markets. We should note that, efficiency is a by-product of competition among entities. Thus, there is a need to carry out a study to assess the contribution of the TPBPA to the improvement of the Tanzania oil products supply chain.

\section{Conclusions}

In this paper, a Grey theory based evaluation model is presented. The model is applied to determine the extent of the applicability of Derivative products by the Tanzanian oil importers. The computational results show that the application of oil derivatives in the Tanzanian oil market is high. In addition, oil forwards which are associated with counter-party default risk are rarely applied for the purchase of oil products by Tanzanian oil product importers. Moreover, the findings reveal that the model based on Grey Theory is a reliable decision making tool for problems involving uncertainty and vagueness. Our future research is to carry out an indepth study assessing the impact of the current Tanzanian policy on the purchasing of oil products from international markets i.e. assessing the role of the TPBPA to the optimization of the Tanzanian supply chains of Oil products.

\section{Acknowledgement}

We would like to thank the TPBPA for their contribution towards our research article.

\section{References}

[1] Shaeri, J., Adaoglu, C. \& Katircioglu, S.T. 2016. Oil price risk exposure: A comparison of financial and non-financial subsectors. Energy, Vol.109: https://doi.org/10.1016/j.energy.2016.05.028.

[2] Liu, C., Chen, J., Li, J. \& Sun, X. 2016. Statistical properties of country risk ratings under oil price volatility: Evidence from selected oil-exporting countries. Energy Policy, Vol.92: 234-245. https://doi.org/10.1016/j.enpol.2016.02.007.

[3] Kakeu, J. \& Bouaddi, M. 2017. Empirical evidence of news about future prospects in the risk pricing of oil assets. Energy Economics, Vol.64: 458-468. https://doi.org/10.1016/j.eneco.2015.10.018.

[4] Lux, T., Segnon, M. \& Gupta, R. 2016. Forecasting crude oil price volatility and value-at-risk: Evidence from historical and recent data. Energy Economics, Vol.56: 117-133.

[5] Nazlioglu, S., Gormus, N.A. \& Soytas, U. 2016. Oil prices and real estate investment trusts (REITs): Gradual-Shift causality and volatility transmission analysis. Energy Economics, Vol.60: 168-175. https://doi.org/10.1016/j.eneco.2016.09.009.

[6] Kristjanpoller, W. \& Minutolo, M.C. 2016. Forecasting volatility of oil price using an artificial neural network-GARCH model. Expert Systems with Applications, Vol.65: 233-241. https://doi.org/10.1016/j.eswa.2016.08.045.

[7] Guo, Y., Wen, X., Wu, Y. \& Guo, and X. 2016 How is China's coke price related with the world oil price? The role of extreme movements. Economic Modelling, Vol.58: 22-33. https://doi.org/10.1016/j.econmod.2016.05.018.

[8] Pal, D. \& Mitra, S.K. 2016. Asymmetric oil product pricing in India: Evidence from a multiple threshold nonlinear ARDL model. Economic Modelling, Vol.59: 314-328. https://doi.org/10.1016/j.econmod.2016.08.003.

[9] Ewing, B.T. \& Malik, F. 2017. Modelling asymmetric volatility in oil prices under structural breaks. Energy Economics, Vol.63: 227233. https://doi.org/10.1016/j.eneco.2017.03.001.

[10] Wang, J. \& Wang, J. 2016. Forecasting energy market indices with recurrent neural networks: Case study of crude oil price fluctuations Energy, Vol.102:

$365-374$ https://doi.org/10.1016/j.energy.2016.02.098.

[11] Tiwari, A.K. \& Albulescu, C.T. 2016. Oil price and exchange rate in India: Fresh evidence from continuous wavelet approach and asymmetric, multi-horizon Granger-causality tests. Applied Energy, Vol.179: 272-283. https://doi.org/10.1016/j.apenergy.2016.06.139.

[12] Ahmadi, M., Behmiri, N.B. \& Manera, M. 2016. How is volatility in commodity markets linked to oil price shocks? Energy Economics, Vol.59: 11-23. https://doi.org/10.1016/j.eneco.2016.07.006.

[13] Mnasri, M., Dionne, G. \& Gueyie, J.P. 2017. The use of nonlinear hedging strategies by US oil producers: Motivations and implications. Energy Economics, Vol. 63: 348-364. https://doi.org/10.1016/j.eneco.2017.02.003.

[14] Liu, L., Wang, Y., Wu, C. \& Wu, W. 2016. Disentangling the determinants of real oil prices. Energy Economics, Vol.56: 363-373. https://doi.org/10.1016/j.eneco.2016.04.003.

[15] Zhang, J. \& Xie, M. 2016. China's oil product pricing mechanism: What role does it play in China's macroeconomy? China Economic Review, Vol.38:

209-221. https://doi.org/10.1016/j.chieco.2016.02.002.

[16] Ji, Q., Fan,Y. \& Geng, J.B. 2014. Separated influence of crude oil prices on regional natural gas import prices. Energy Policy, Vol.70: 96-105. https://doi.org/10.1016/j.enpol.2014.03.019.

[17] Chen, Y., Zou,Y., Zhou,Y. \& Zhang, C. 2016. Multi-step-ahead crude oil price-Forecasting based on Grey Wave Forecasting Method. Procedia Computer Science, Vol. 91: 1050-1056. https://doi.org/10.1016/j.procs.2016.07.147.

[18] Guay, W.R. 1999. The impact of derivatives on firm risk: An empirical examination of new derivative users. Journal of Accounting and Economics, Vol.26 (1-3): 319-351. https://doi.org/10.1016/S0165-4101(98)00032-9.

[19] Ma, J., Liu,J., Huang, D. \& Chen, W. 2017. Forecasting the oil futures price volatility: A new approach. Economic Modelling, Vol.64 560-566. https://doi.org/10.1016/j.econmod.2017.04.020.

[20] Phan, D., Nguyen,H. \& Faff, R. 2014. Uncovering the asymmetric linkage between financial derivatives and firm value - The case of oil and gas exploration and production companies. Energy Economics, Vol.45: 340-352. https://doi.org/10.1016/j.eneco.2014.07.018.

[21] Turner, P.A. \& Lim. S.H. 2015. Hedging jet fuel price risk: The case of U.S. passenger airlines. Journal of Air Transport Management, $\quad$ Vol.44-45: 54-64. https://doi.org/10.1016/j.jairtraman.2015.02.007.

[22] Yu, J., Zhang, X. \& Xiong, C. 2017. A methodology for evaluating micro-surfacing treatment on asphalt pavement based on grey system models and grey rational degree theory. Construction and Building Materials, Vol.150: https://doi.org/10.1016/j.conbuildmat.2017.05.181.

[23] Zhicheng, Y., Lijun, W., Zhaokuo, Y. \& Haowen, L. 2017. Shape optimization of welded plate heat exchangers based on grey correlation theory. Applied Thermal Engineering, Vol.123: 761-769. https://doi.org/10.1016/j.applthermaleng.2017.05.005.

[24] Rajeswari, B. \& Amirthagadeswaran, K.S. 2017. Experimental investigation of machinability characteristics and multi-response optimization of end milling in aluminium composites using RSM based grey relational analysis. Measurement, Vol. 105: 78-86. https://doi.org/10.1016/j.measurement.2017.04.014.

[25] Baruah, A., Pandivelan, C. \& Jeevanantham, A.K. 2017. Optimization of AA5052 in incremental sheet forming using grey relational analysis. Measurement, Vol. 106: 95-100. https://doi.org/10.1016/j.measurement.2017.04.029.

[26] Mathivathanan, D., Govindan, K. \& Haq, A.N. 2017. Exploring the impact of dynamic capabilities on sustainable supply chain firm's performance using Grey-Analytical Hierarchy Process. Journal of Cleaner Production, Vol. 147: 637-653. https://doi.org/10.1016/j.jclepro.2017.01.018.

[27] Thakur, V. \& Ramesh, A. 2015. Selection of Waste Disposal Firms Using Grey Theory Based Multi-criteria Decision Making Technique. Procedia-Social and Behavioral Sciences, Vol.189: 81-90. https://doi.org/10.1016/j.sbspro.2015.03.202.

[28] Wei, J., Zhou, L., Wang, F. \& Wu, D. 2015. Work safety evaluation in Mainland China using grey theory. Applied Mathematical Mod$\begin{array}{llll}\text { elling, } & \text { Vol. } & \text { 39(2): }\end{array}$ https://doi.org/10.1016/j.apm.2014.06.017.

[29] Yan, F., Qiao, D., Qian, B., Ma, L., Xing, X., Zhang, Y. and Wang, X. 2016. Improvement of CCME WQI using grey relational method. Journal of Hydrology, Vol.543 (B): 316-323.

[30] Golinska, P., Kosacka, M., Mierzwiak, R. \& Werner-Lewandowska, K. 2015. Grey Decision Making as a tool for the classification of the sustainability level of remanufacturing companies. Journal of Cleaner Production, Vol. 105: 28-40. https://doi.org/10.1016/j.jclepro.2014.11.040.

[31] Chithambaranathan, P., Subramanian, N., Gunasekaran, A. \& Palaniappan, P.L.K. 2015. Service supply chain environmental performance evaluation using grey based hybrid MCDM approach. In- 
ternational Journal of Production Economics, Vol. 166: 163-176. https://doi.org/10.1016/j.ijpe.2015.01.002.

[32] Rajesh, R. \& Ravi, V. 2015. Supplier selection in resilient supply chains: a grey relational analysis approach. Journal of Cleaner Production, $\quad$ Vol.86: 343-359. https://doi.org/10.1016/j.jclepro.2014.08.054.

[33] Baskaran, V., Nachiappan, S. \& Rahman, S. 2012. Indian textile suppliers' sustainability evaluation using the grey approach. Inter national Journal of Production Economics, Vol.135 (2): 647-658. https://doi.org/10.1016/j.ijpe.2011.06.012.

[34] Celikbilek, Y. \& Tüysüz, F. 2016. An integrated grey based multicriteria decision-making approach for the evaluation of renewage energy sources. Energy, Vol.115 (Part 1): 1246-1258. https://doi.org/10.1016/j.energy.2016.09.091.

[35] Deng, J.L. 1982. The introduction of grey system. The Journal of Grey System, 1(1): 1-24.

[36] Yang, Y, and John, R. 2012. Grey sets and greyness. Inform. Sci., 185: 249-264. https://doi.org/10.1016/j.ins.2011.09.029.

[37] Liu, S., Fang, Z., Yang, Y. \& Forrest, J. 2012. General grey numbers and their operations, Grey systems: Theory and Application, 2(3): 341-349.

[38] Massami, E.P. \& Myamba, B.M. 2016. Application of Vague Analytical Hierarchy Process to Prioritize the Challenges Facing Public Transportation in Dar Es Salaam City - Tanzania. International Journal of Advanced Research in Artificial Intelligence, Vol. 5(3): 46-53. 